\title{
A Study on Effective System for Harbor Container Delivery \& Cargo Work Automatuion
}

\author{
Dong-Hoon Kim, Jun-Yeob Song ${ }^{1}$, Seung-Ho Lee, Il-Yong Kang ${ }^{2}$, Suk-Keun Cha ${ }^{3}$ \\ ${ }^{1}$ Intelligent Manufacturing Systems Research Division, Korea Institute of Machinery \& Materials, Daejeon, Korea \\ ${ }^{2} R \& D$ Center, Promecs Co., Ltd., Jeonju, Korea \\ ${ }^{3}$ ACS Co., Ltd., Seoul, Korea \\ E-mail: \{kdh680, sjy658\}@kimm.re.kr, \{shlee, irion\}@promecs.com \\ Received June 2, 2010; revised June 10, 2010; accepted June 17, 2010
}

\begin{abstract}
In this article, we have attempted to analyze current situation and the problem of domestic and overseas harbor container delivery \& cargo work automation centered on major harbors and to suggest effective way to deal with the issue in order to improve the productivity of container cargo work per crane, the major index of productivity of high value-added shipbuilding industry. In particular, we have suggested the way to realize effective automation system that can improve the efficiency of harbor container delivery \& cargo work through the development of high-tech measuring automation technology using microwave radar and applied design that have broken away from traditional automation system and traditional problems such as dependence on manual work and the problem of laser method in which workers cannot identify laser beam under sunlight and workers' eyesight can be weakened by being exposed to laser beam.
\end{abstract}

Keywords: Harbor, Container, Delivery, Cargo Work, Automation

\section{Introduction}

Shipbuilding industry is undeniably high value-added industry with domestic, overseas competitiveness and will be developed continuously in the future. In shipbuilding industry, harbor is a work place as well as an important factor determining productivity as shown in Figure 1. Harbor has close relation with crane and the productivity of container cargo work per crane is a representative index by which we can measure the service level of a harbor and the productivity per shipment can be considered more reasonable index recently. As shown Table 1 and Figure 2, Busan harbor, the representative port of South Korea, is ranked high among Asian ports in terms of capacity in container transportation. However, its container productivity per crane is about 25.1 containers per hour, which is the lowest level except Kaohsiung port in Taiwan compared with Hong Kong (40) and Singapore (39.4) etc. Thus, effective management of yard cargo work is necessary to improve port productivity including Busan harbor. It is absolutely necessary to improve container cargo work by focusing on the system automation within the area of apron (the part attached to the inner wall of port dock and a place where container cargo work is conducted by container crane) in container cargo work automation for this purpose. In this article, we have suggested the effective way to overcome the problem and developed a prototype device by analyzing current situation and the problems of related method.

\section{Current Situation of Domestic and Overseas Harbor Container}

In case of domestic existing ports, most of the work is done manually due to outdated infrastructure and the opposition of port trade union and Hanjin shipping co. applied laser beam method to the new Gamman dock in Busan harbor in terms of automation but it is being managed along with manual work including dispatching guide staff in a rainy or foggy day. In most cases, proper number of staff to guide containers to arrive at cargo work area of crane is estimated to be about 7 but 48 people are being dispatched per container crane in three 8-hour shifts in reality to avoid danger or overwork, which is creating excessive fixed costs and weakening business competitiveness. 
Table 1. Crane Productivity of major ports.

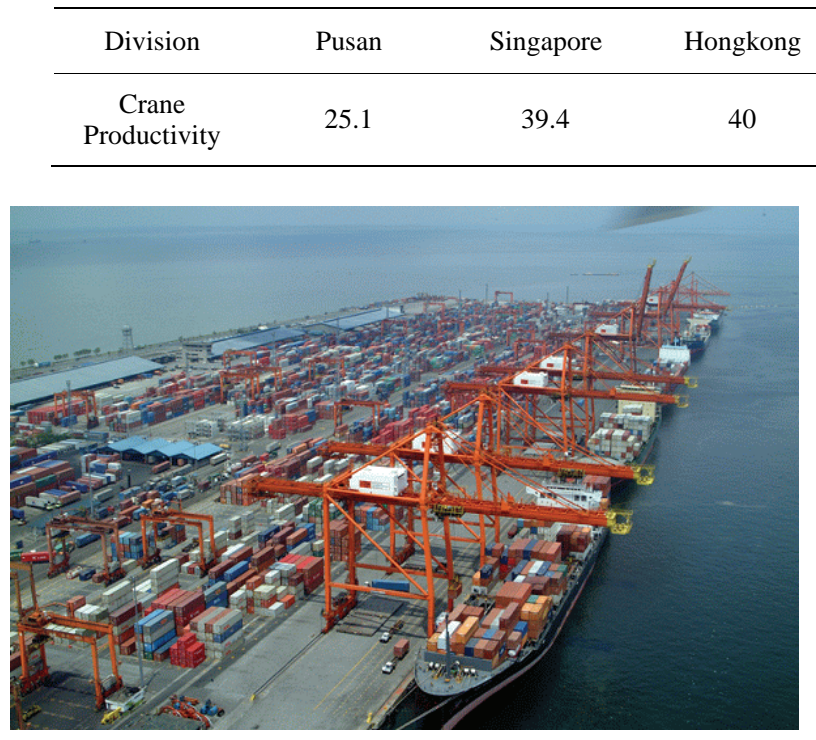

Figure 1. Container loading dock.

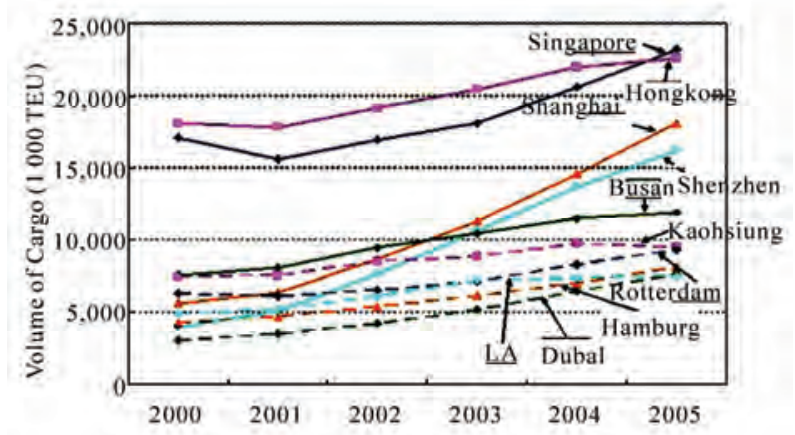

Figure 2. Comparison of volume of cargo between major ports.

Crane maintenance rate of operation is about $60 \%$ considering proper rate of operation to cope with the change of volume of cargo and actual working hour is estimated to be about 4.8 hours and workers spend $40 \%$ of 8 hour daily working time (3.2 hours) for standby time since workers are dispatched by crane unit.

But U-Port project was initiated by the former Ministry of Maritime Affairs \& Fisheries in Korea and is under way currently and Gwang Yang port, as an example, began the construction of Automated Terminal in 2003 and is expected to start test-operation in 2009, which seems to create high expected effect for competitiveness and high value-added industry in the future.

As shown in Figure 3, the domestic and overseas research trend of related technology is as follows. In Korea, a method that finds the route by receiving information about transport vehicle's stop location manually through assistant worker positioned outside has been used recently in most case and the research about technology

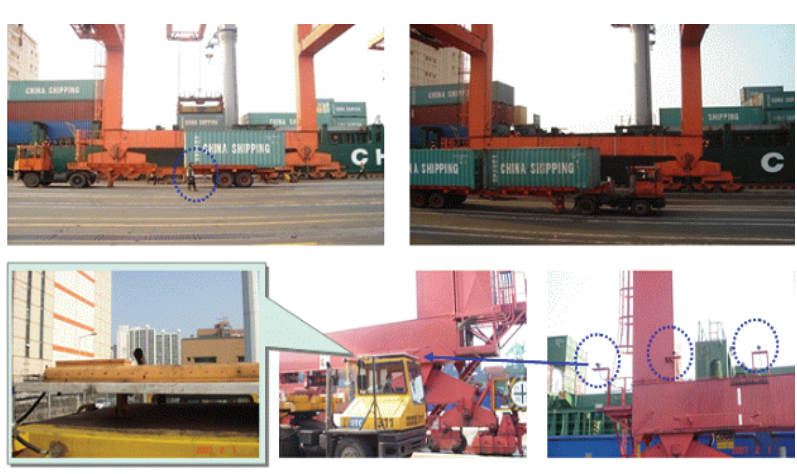

Figure 3. Introduction of traditional system.

using optical sensor, optical fiber and camera are being conducted partly but its application on the field is difficult due to noise etc. In case of foreign countries, there are HHLA port, Hamburg, Rashid port, Dubai, Melbourne port, Australia, Katka port, Finland, and Salerno port, Italia etc as examples of using laser and there are Vancom terminal and Delta terminal of Vancouver port, Canada etc as examples of using RF Tag. But there are problems in these cases in which the angel of laser beam changes due to crane vibration because the device needs to be installed on the crane itself in case of laser beam; the credibility and recognition rate drop due to environmental factors occurring frequently such as direct sunlight, lighting, rainy weather, heavy rainfall, fog, and dust; the risk of safety accident, such as weakening of eyesight or losing eyesight when the eyes of worker are exposed to laser beam, is high; it is difficult to process various information; and the application of camera is not effective either because there are many days with bad weather such as fog etc.

Other than these cases, ultrasound can be used additionally for collision prevention due to the limitation of measuring range and RF Tag is being used for limited ID monitoring to establish management information system concerning electronic document exchange information and loading control such as yard schedule planning and ship transport planning as part of information system.

\section{Effective Way of Container Delivery \& Cargo Work Automation}

The development of a device that provides the stop location of Yard Trailer is required in case of cargo work of loading and unloading container by crane between Ship and Yard Trailer (Y/T) as an effective way of container 
delivery \& cargo work automation. For this goal, the development of hardware and software meeting the requirement of the field characteristics of port without being interrupted by various external environments is necessary. It is required to develop position measure system based on RF that consists of Transponder and Base Station, control system that transmits or processes the position information received from the system to the driver of transport vehicle (refers to control device in case of Automatic Guided vehicle), and controller that transmits and processes the stop position information of vehicle calculated in one of the base stations installed on multiple crane supporters to transport vehicle wirelessly in case of transport vehicle and base station.

In other words, it is necessary to research the way to make precise tracking of position possible, processing technology of various sensor data, position measure method based on RF, and application of system. It is considered as an effective way for container delivery \& cargo work automation to develop high-tech measurement automation technology using microwave radar system that overcame traditional system with problems such as dependence on manual work and identification problem in case of rainy or bad weather etc, to improve the performance port automation system through applied design and to achieve localization of the system. It will become a solution meeting the requirement of field characteristics of port while minimizing interruption from various external environments. As shown in Figure 4, the detailed specification of port automation system to improve container delivery \& cargo work can be defined as follows. Also, Figure 5 shows the overview of management solution and function for suggested system.

1) Develop Automatic Recognition Function by each Container Size.

2) Develop Position \& Tracking Solution.

3) Ensure necessary performance under bad condition such as temperature $\left(-20^{\circ} \mathrm{C}\right.$ to $\left.70^{\circ} \mathrm{C}\right)$, humidity(snow, rain, fog), and wind etc.

4) Enable recognition and cargo work for the next generation Twin Lift.

5) Decide the position of Yard Crane (RTTC), Tracking Solution, and Embedded Type Device.

\section{The Development of Prototype Device}

The purpose of developing prototype device in this research is to enable precise tracking of position and to research processing technology of various sensor data, position measurement method based on RF and application of system. The purpose is to develop high-tech measurement automation technology using microwave radar system that overcame traditional system with problems such as dependence on manual work and identification problem in case of rainy or bad weather etc, to improve the performance of port automation system through applied design and to achieve localization of the system. For this purpose, we plan to develop hardware and software meeting the requirement of field characteristics of port without being interrupted by various external environment.

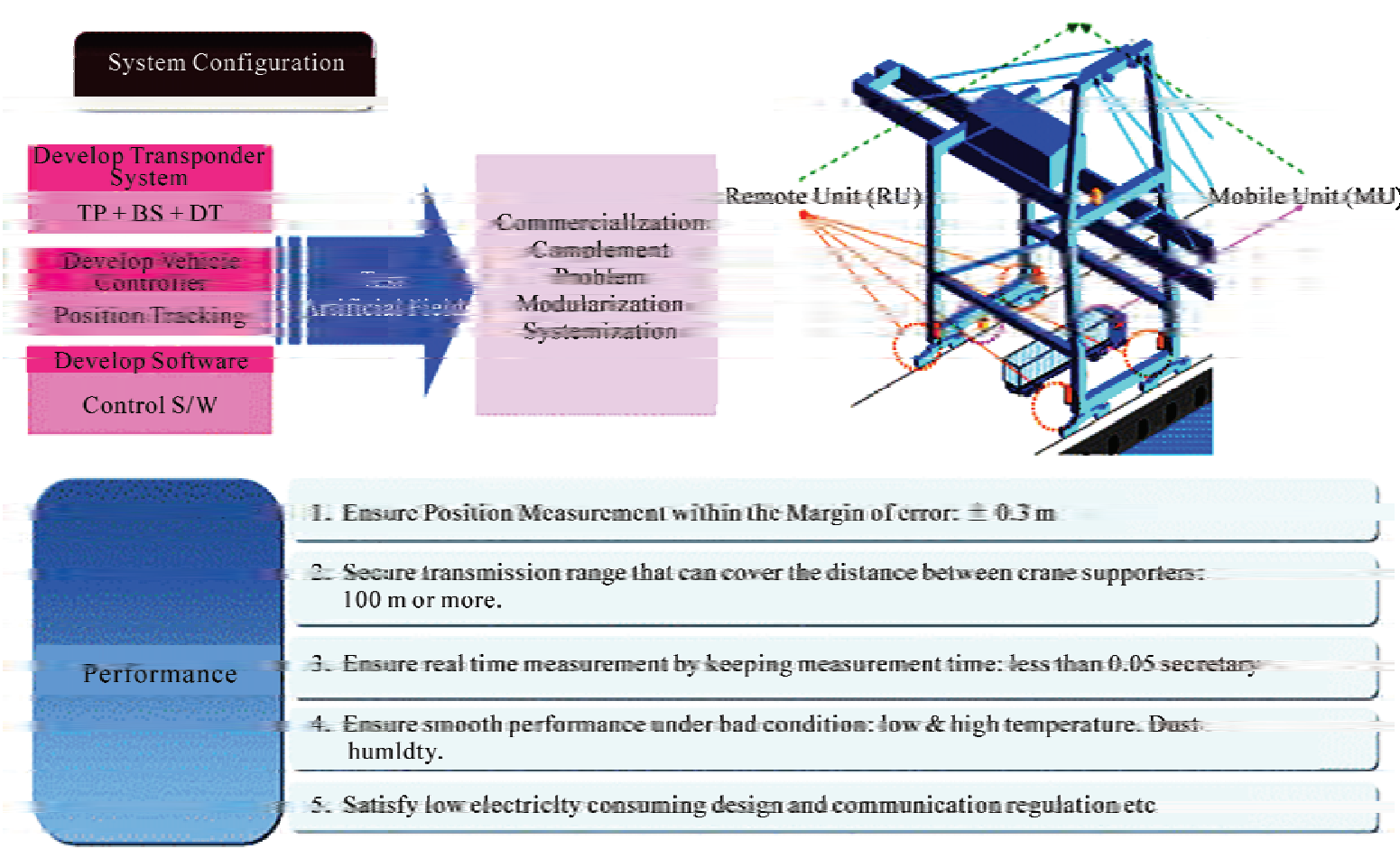

Figure 4. The goal and performance of automation system for delivery \& cargo work. 


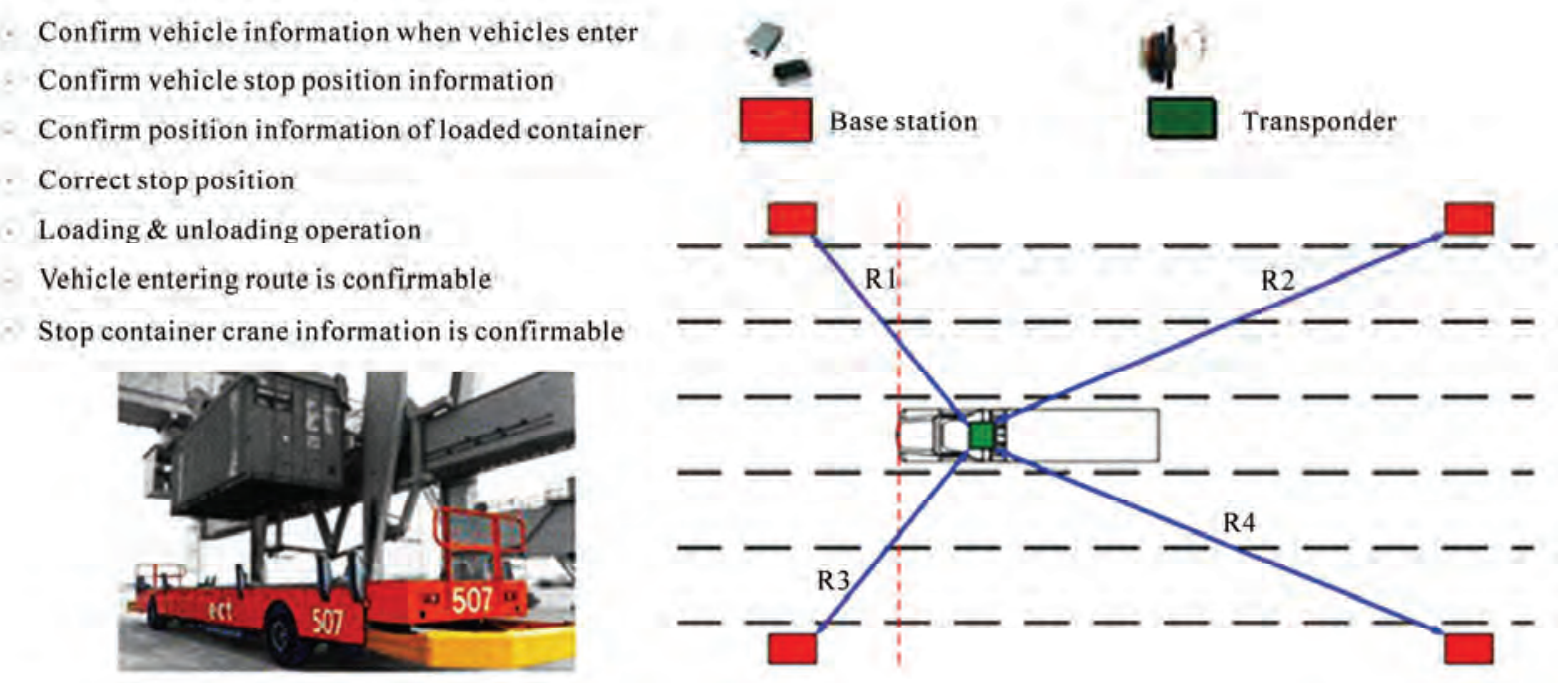

Figure 5. Overview of management solution and function.

In other words, we have suggested development system and implemented basic design to satisfy the specification (transmission range: more than $100 \mathrm{~m}$, margin of error: less than $\pm 0.3 \mathrm{~m}$ ) for the final goal of developing position measurement system based on RF suitable for port environment that consists of Transponder and Base station, control system that transmits or processes position information received from the system to the driver of transport vehicle (refers to control device in case of AGV), and controller that transmits and processes stop position information calculated in one of the base stations installed on multiple crane supporters in case of transport vehicle and base station.

In development prototype system, TP (Transponder), which receives signal from BS (Base station) located at 4 legs of container crane as shown in Figure 6, receives information from the distance of R1, R2, R3, R4 and the information gets converted to position information by controller. The internal system configuration and operation diagram of overall system are shown in Figure 7 and Figure 8.

Figure 9 shows monitoring device and the design contents of monitoring screen to manage development prototype system effectively. BS (base station) and TP (Transponder) send and receive information from each other in 5.8 GHz frequency band between Yard Trailer and Crane and monitoring device for vehicle provides the information to driver through user interface and the information gets transmitted to operation control room (situation room) in $2.4 \mathrm{GHz}$ frequency band so that monitoring is made possible in control room.

As shown Figure 10, in terms of calculating position, the position of moving unit (MU) is determined by measuring the distance to 3 fixed units (RU) (minimum theoretical number). The followings are the calculation meth- ods and we proceeded with research using RTOF method.

1) TDOA (Time-difference of arrival)

2) RTOF (Round-trip time-of-flight)

3) FMCW(Linear frequency modulation)

Measurement mechanism can be explained simply as follows. The distance (D) between TP and BS is calculated by TOA method (Time of arrival) using RTT (round trip time). TOA method using RTT determines the time in which a signal gets transmitted between BS and TP from the time in which a signal travels back and forth between BS and TP. Coordinates of each $\operatorname{TP}\left(\mathrm{x}_{1}, \mathrm{y}_{1}, \mathrm{H}\right)$, $\left(x_{2}, y_{2}, H\right),\left(x_{3}, y_{3}, H\right)$, and the height of $B S\left(H^{\prime}\right)$ are known values and $\mathrm{D}_{1}, \mathrm{D}_{2}, \mathrm{D}_{3}$ are calculated by TOA method. $\mathrm{D}_{1}{ }^{\prime}, \mathrm{D}_{2}{ }^{\prime}, \mathrm{D}_{3}$ ' can be calculated by the Pythagorean formula because the values of $\mathrm{D}_{1}, \mathrm{D}_{2}, \mathrm{D}_{3}$ and $\mathrm{H}-\mathrm{H}^{\prime}$ are already known. Thus, if you substitute all values into the following equation, you will get 3 Equations about $x$, $\mathrm{y}$, by which you can calculate the coordinates(x, y).

$$
\begin{aligned}
D_{1}^{\prime} & =\sqrt{D_{1}^{2}-\left(H-H^{\prime}\right)^{2}} \\
& =\sqrt{\left(x-x_{1}\right)^{2}+\left(y-y_{1}\right)^{2}} \\
D_{2}^{\prime} & =\sqrt{D_{2}^{2}-\left(H-H^{\prime}\right)^{2}} \\
& =\sqrt{\left(x-x_{2}\right)^{2}+\left(y-y_{2}\right)^{2}} \\
D_{3}^{\prime} & =\sqrt{D_{3}^{2}-\left(H-H^{\prime}\right)^{2}} \\
& =\sqrt{\left(x-x_{3}\right)^{2}+\left(y-y_{3}\right)^{2}}
\end{aligned}
$$

In order to conduct a mock test, we formulated Auto routing and Firmware module as shown in Figure 11 and plan to monitor moving position between Container crane 


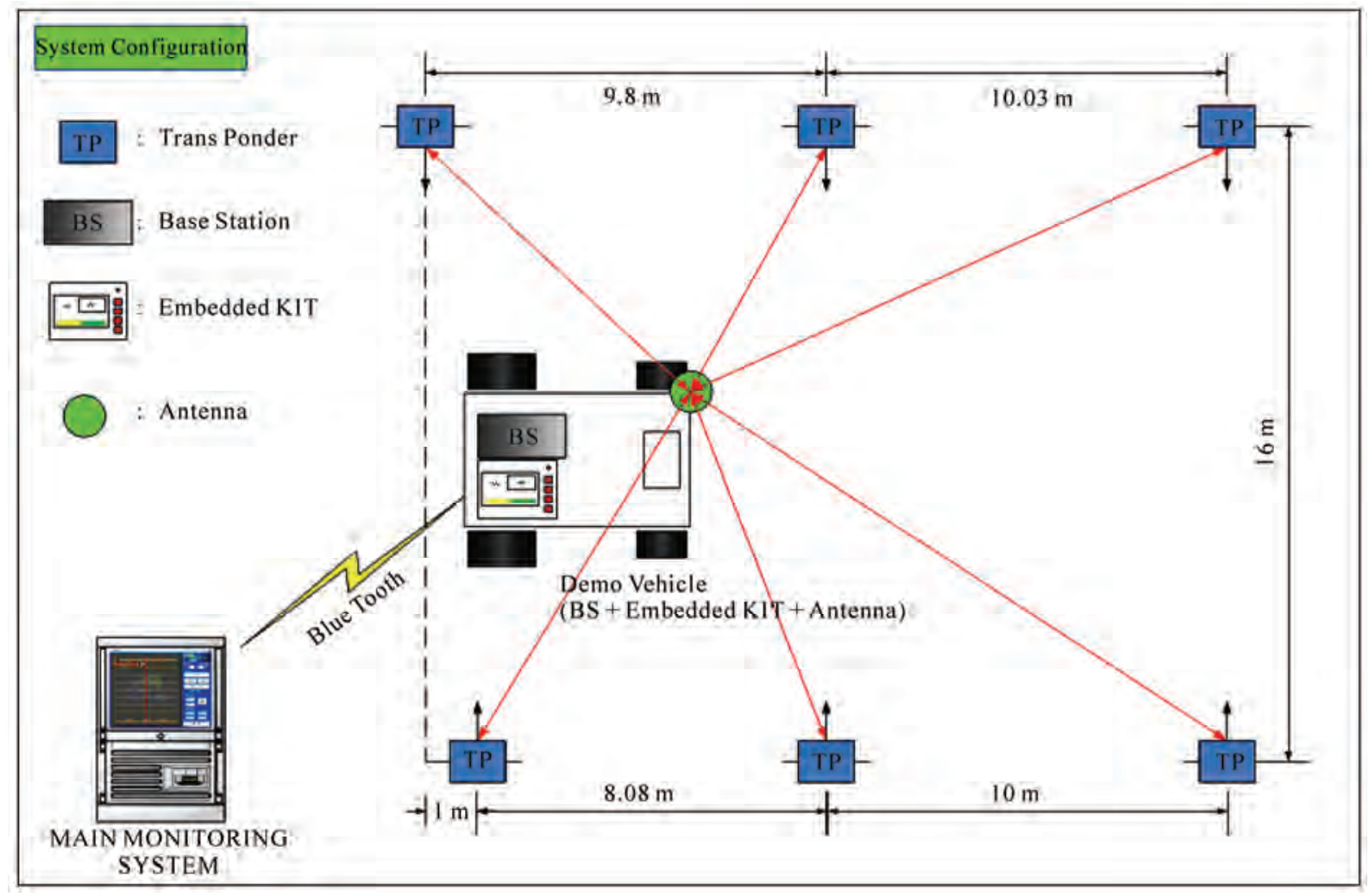

Figure 6. Overview of development prototype system.

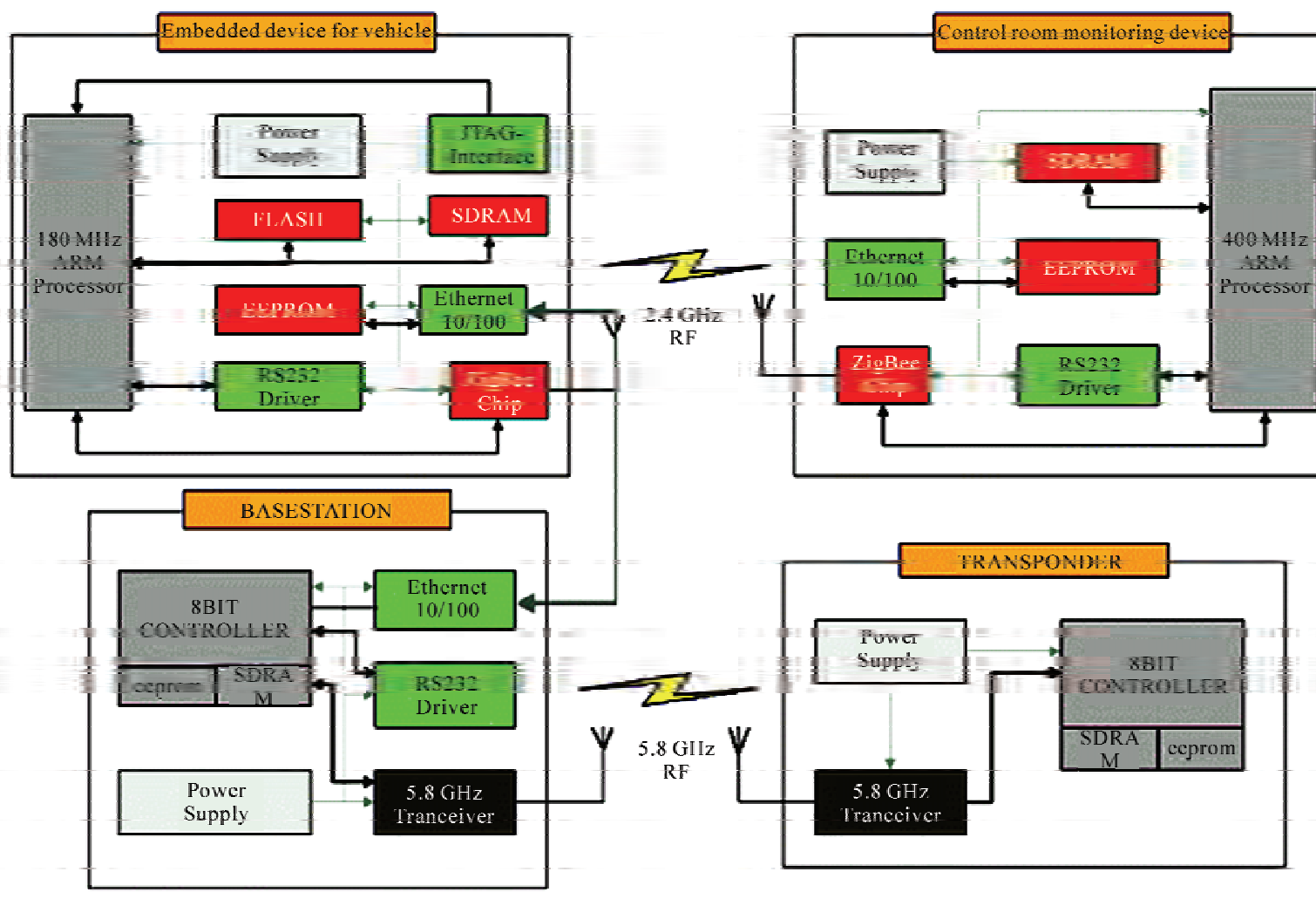

Figure 7. Internal system configuration. 


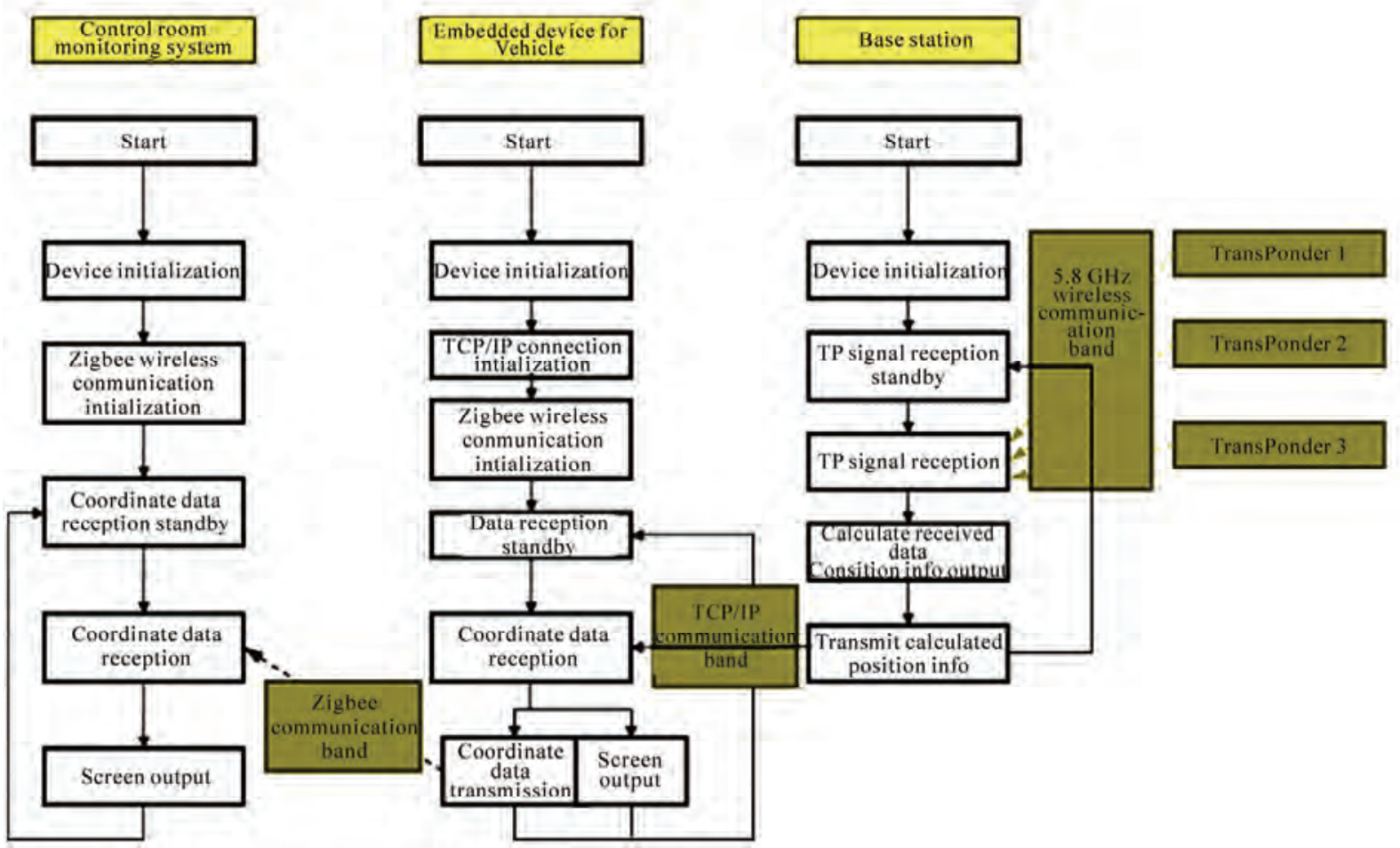

Figure 8. System operation diagram.

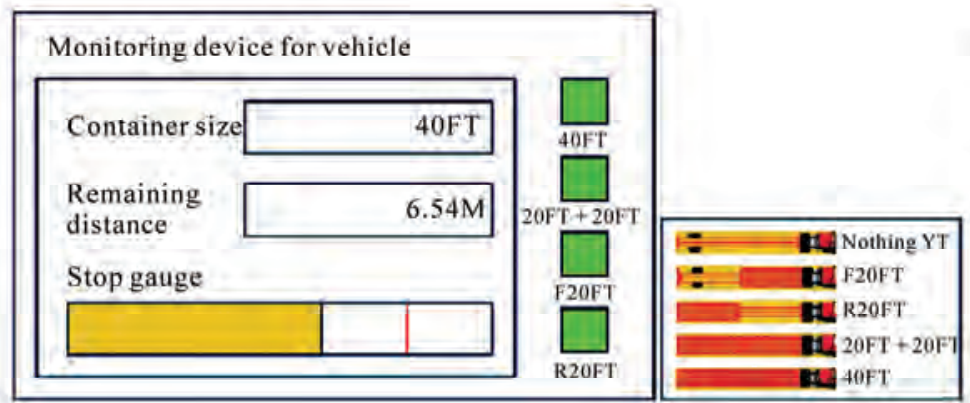

Embeded device forvehicle spec example Size: $180 \mathrm{~mm} \times 130 \mathrm{~mm} \times 40 \mathrm{~mm}$ CPU: $180 \mathrm{MHz}$ ARM Processor RAM: 32 Mbytes

Ethernet: 10/100 Base

Serial: RS-232

Wireless Com: $2.4 \mathrm{Ghz}(\mathrm{Z})$ or $5.8 \mathrm{Ghz}$ (ISM)

Margin of error: $+1-0.3 \mathrm{~m}$

LCD: $640 \times 480$

Operation room monitoring program

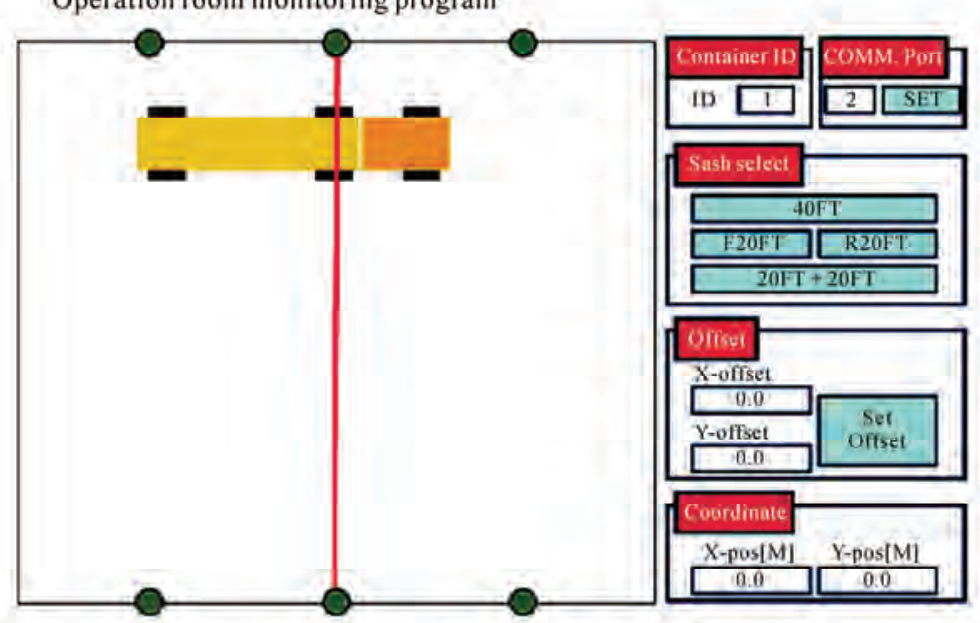

Control room monitoring spec example Size: $300 \mathrm{~mm} \times 200 \mathrm{~mm} \times 80 \mathrm{~mm}$ CPU: $400 \mathrm{MHz}$ ARM Processor RAM: 64 Mbytes Ethernet: $10 / 100$ Base

Serial: RS-232

Wireless Communication:

$2.4 \mathrm{Ghz}$ Zigbee

USB: USB2.0

LCD: $640 \times 480$

Figure 9. Monitoring device and monitoring screen design. 


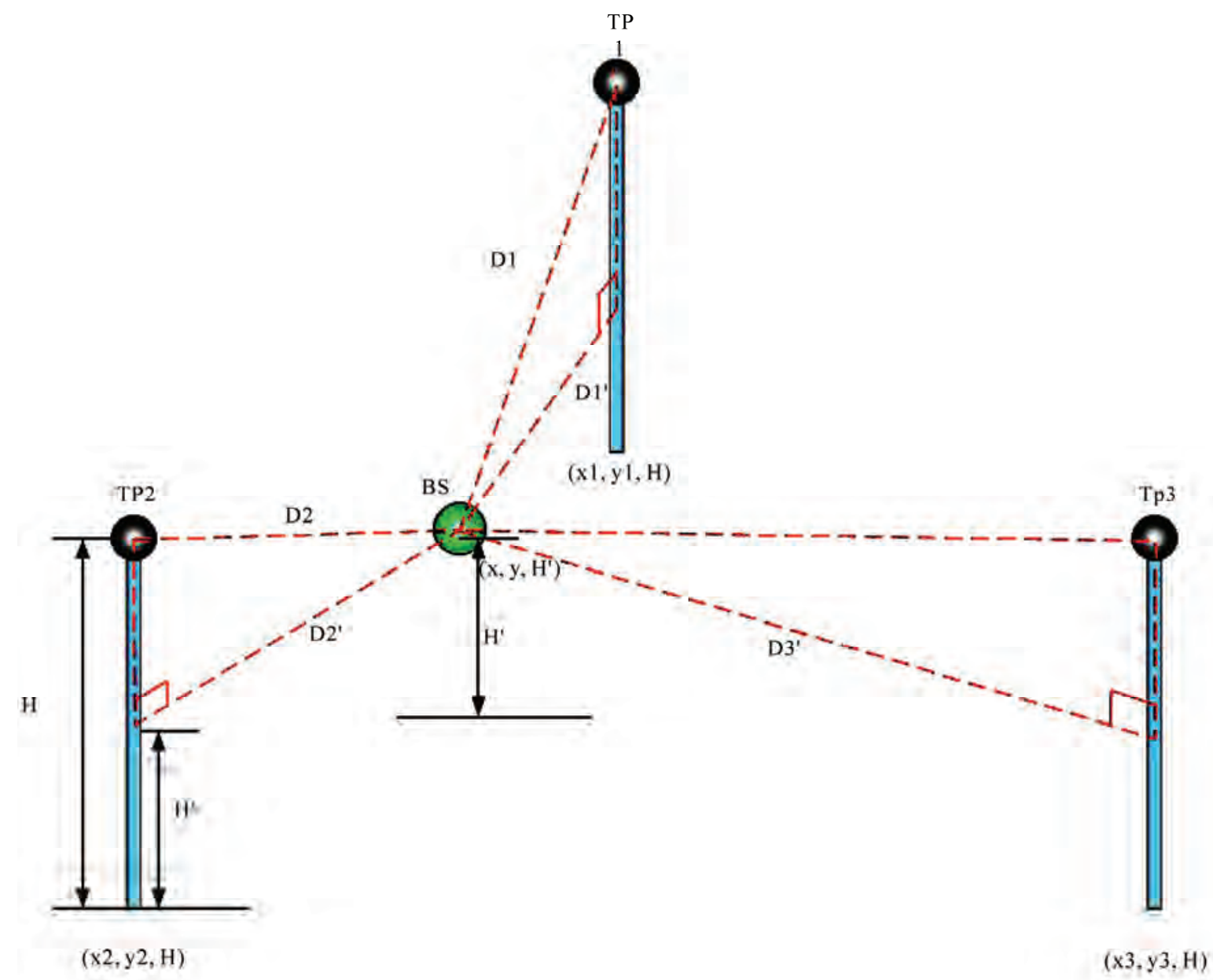

Figure 10. Measurement mechanism.

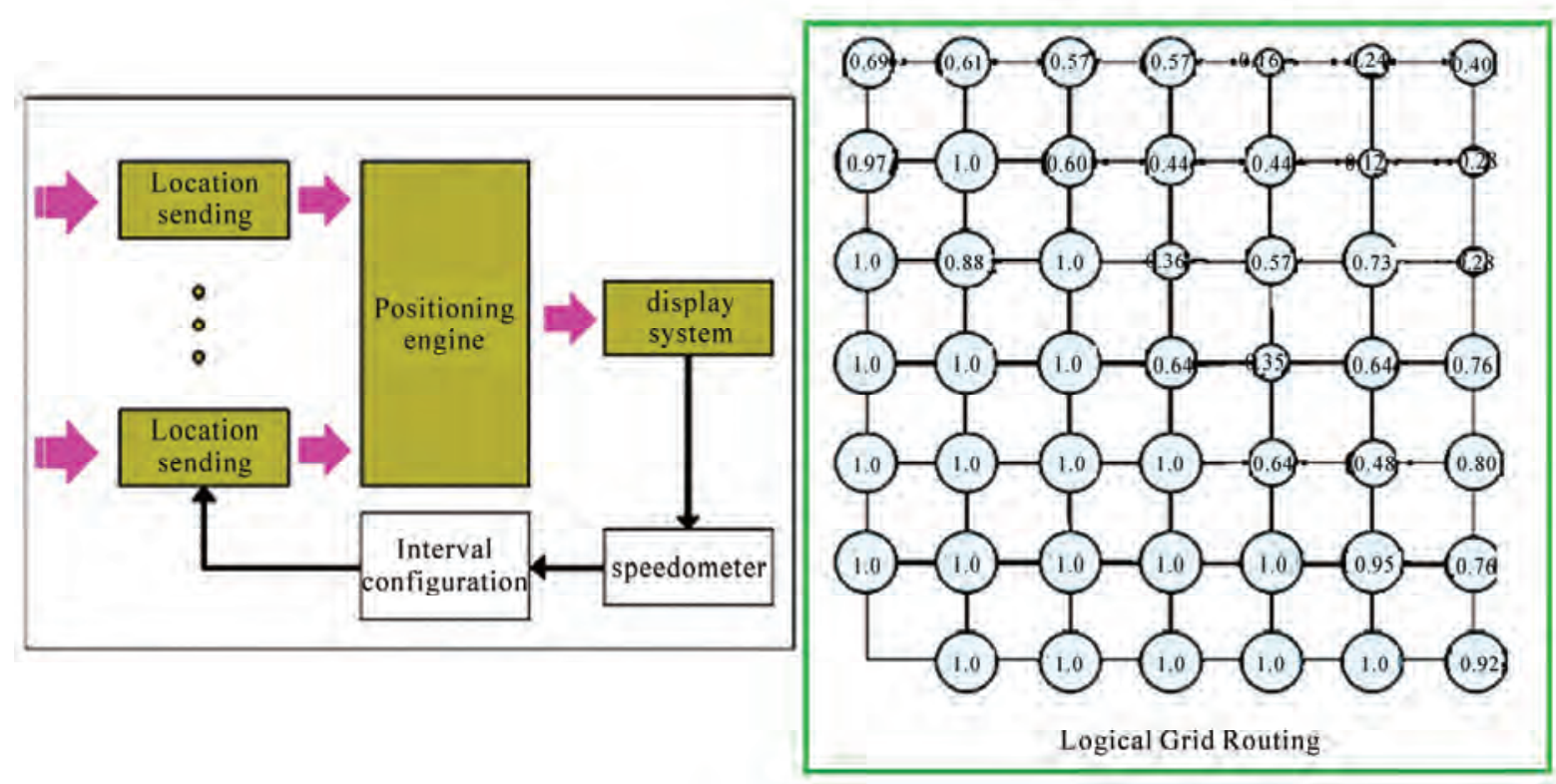

Figure 11. Design of auto routing and firmware module. 
and Yard trailer on this basis. We also developed embedded prototype device for Yard Trailer $(\mathrm{Y} / \mathrm{T})$ as shown in Figure 12 on the basis.

\section{Operation Result}

As shown in Figure 13 and Figure 14, we confirmed that the gauge of Embedded KIT installed in Demo Vehicle reached red line and that the time indicating the distance is zero and the time indicating container of container monitoring program is at the middle point were meeting at the same point.

For error test at randomly fixed position, it is an experiment to find out hunting level of data by collecting raw data when vehicle is stopped at a random position. As shown in Table 2, we confirmed that the average error was less than $30 \mathrm{~cm}$ in all cases as the result of measuring more than 2 positions (coordinates) 5 times for 30 seconds.

For error test in case of returning to starting point, we measured the first position we measured and position accuracy when Demo Vehicle returned to starting point. It is a test to find out whether the system can always identify the same position information. As the result of measurement shown in Table 3, the position accuracy when Demo vehicle returned to starting point was less than $7 \mathrm{~cm}$ in maximum, which is very good result. We also confirmed that the system can identify the same position information in any situation.

For error test according to the number of TP, we conducted a test by turning off the power of TP with Demo

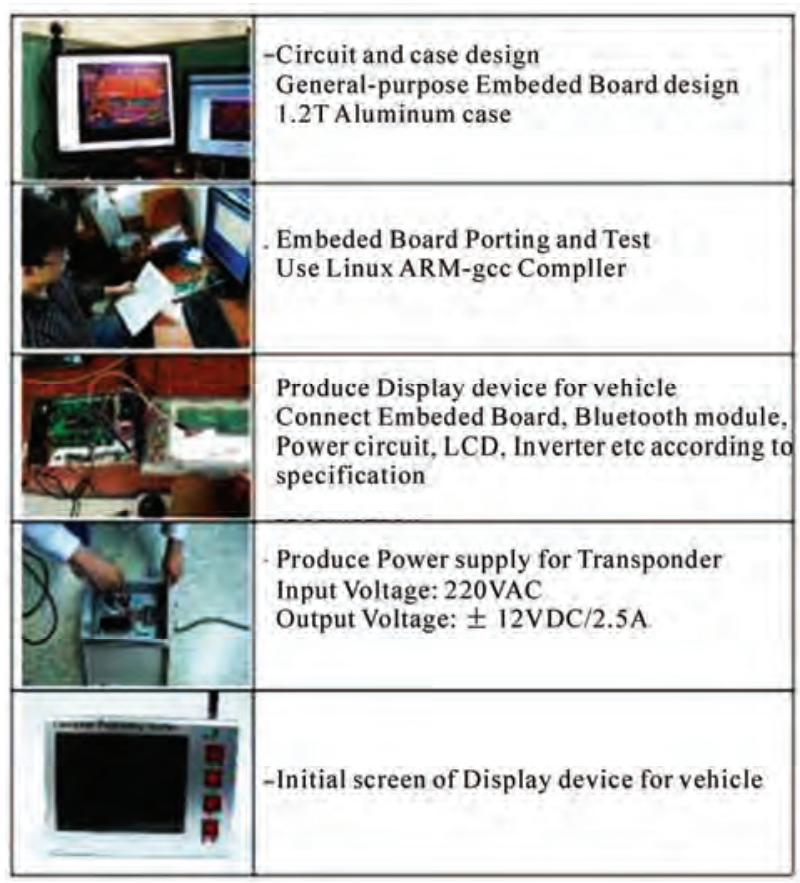

Figure 12. Design of monitoring system in control room.

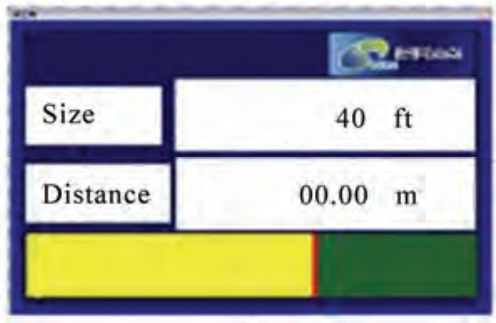

Figure 13. Embedded KIT monitoring screen.

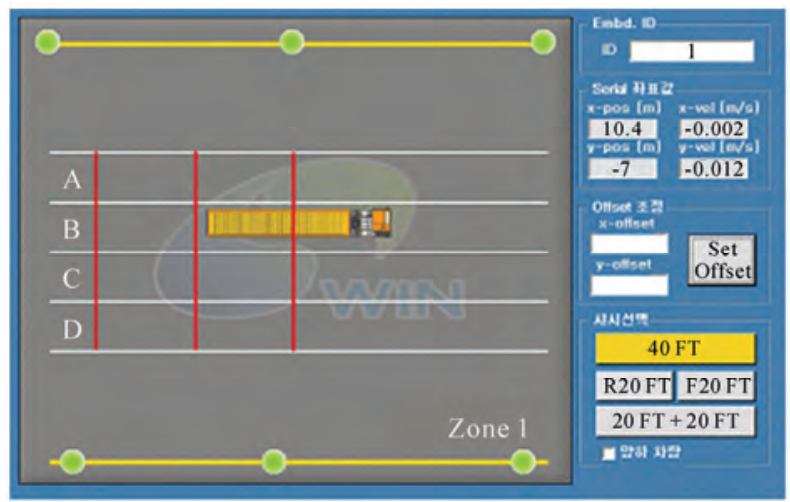

Figure 14. Main monitoring screen.

Table 2. The result of error test at randomly fixed position.

\begin{tabular}{ccc}
\hline Measured coordinates & $(11.4,-8)$ & $(20.4,-6.1)$ \\
\hline $\begin{array}{c}\text { Average measured } \\
\text { coordinates }\end{array}$ & $11.36,-7.91$ & $20.36,-6.02$ \\
Average Error & x: $4 \mathrm{~cm}, \mathrm{y}: 9 \mathrm{~cm}$ & $\mathrm{x}: 4 \mathrm{~cm}, \mathrm{y}: 8 \mathrm{~cm}$ \\
\hline
\end{tabular}

Table 3. The result of Error Test in case of returning to starting point.

\begin{tabular}{ccc}
\hline $\begin{array}{c}\text { Measured } \\
\text { coordinates }\end{array}$ & $\begin{array}{c}\text { First measurement } \\
(10.7,-8.1)\end{array}$ & $\begin{array}{c}\text { measurement after return } \\
(10.7,-8.1)\end{array}$ \\
\hline $\begin{array}{c}\text { Average measured } \\
\text { coordinates }\end{array}$ & $10.73,-8.15$ & $10.73,-8.15$ \\
Average Error & x: $2 \mathrm{~cm}, \mathrm{y}: 7 \mathrm{~cm}$ & x: $3 \mathrm{~cm}, \mathrm{y}: 5 \mathrm{~cm}$ \\
\hline
\end{tabular}

Table 4. The result of Error Test according to the number of TP.

\begin{tabular}{cc}
\hline Number of TP & Average Error \\
\hline 3 & $\mathrm{x}: 14.3 \mathrm{~cm}, \mathrm{y}: 8.3 \mathrm{~cm}$ \\
4 & $\mathrm{x}: 11.3 \mathrm{~cm}, \mathrm{y}: 3 \mathrm{~cm}$ \\
5 & $\mathrm{x}: 12.5 \mathrm{~cm}, \mathrm{y}: 14 \mathrm{~cm}$ \\
6 & $\mathrm{x}: 5 \mathrm{~cm}, \mathrm{y}: 8.5 \mathrm{~cm}$ \\
\hline
\end{tabular}

Vehicle located at a random position. We used 3-6 TPs and it is a test about TP that cannot secure LOS and this test was conducted to prepare against poles or cargo in case of moving. As the result of measurement shown in 
Table 4, there was a little difference of error according to the number of TP but the margin of error in all cases was less than $30 \mathrm{~cm}$.

Table 5 shows the summary of the contents and result of these experiments. The excellence of development system compared with traditional system can be expected as the result of this research as shown in Table 6.

\section{Conclusions}

Automation system between crane and yard trailer to improve container delivery \& cargo work is an original technology that can prepare for the centralization of port container volume, which will have ripple effect on the economy. In terms of the effectiveness of container crane used for port cargo work currently, 48 workers are being dispatched per crane in 38-hour shifts; Crane maintenance rate of operation is about $60 \%$ considering proper rate of operation to cope with the change of volume of cargo; workers spend $40 \%$ of 8 hour daily working time (3.2 hours) for standby time since workers are dispatched by crane unit, which has been causing excessive fixed costs and weakening business competitiveness. It is concluded that we can be well prepared for the centralization of port container volume of cargo due to the pursuit of building bigger and faster ships through the development

Table 5. Summary of test result.

\begin{tabular}{|c|c|}
\hline Test & Level of achievement \\
\hline Error Test at random fixed position & $\begin{array}{l}\text { Confirm the credibility of data by collecting raw Confirmd that average error was less than } 30 \mathrm{~cm} \\
\text { data when demo vehicle is stopped at a random in all cases after measuring more than } 2 \text { positions } \\
\text { location } \\
\text { (coordinates) } 5 \text { times for } 30 \text { seconds. }\end{array}$ \\
\hline $\begin{array}{l}\text { Error Test in case of returning to start- } \\
\text { ing point }\end{array}$ & 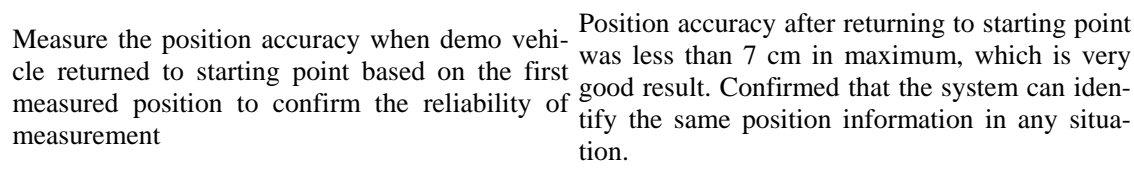 \\
\hline $\begin{array}{l}\text { Error Test according to the number of } \\
\qquad \text { TP }\end{array}$ & $\begin{array}{l}\text { Test by turning off power supply of TP with } \\
\text { demo vehicle located at random position, Test There was a little difference of error according to } \\
\text { using 3-6 TPs to prepare for a situation in which the number of TP but the margin of error was } \\
\text { LOS cannot be secured such as poles or cargo less than } 30 \mathrm{~cm} \text { in all cases. } \\
\text { etc. }\end{array}$ \\
\hline Operation Test & $\begin{array}{l}\text { Test to confirm vehicle stop through Embedded Confirmed that the system operated normalloy as } \\
\text { Kit in demo vehicle and monitoring program. the result of mock test using demo vehicle. }\end{array}$ \\
\hline
\end{tabular}

Table 6. Comparison between development system and traditional system.

\begin{tabular}{|c|c|c|}
\hline Item & $\begin{array}{c}\text { Traditional system (Laser scanner, beam, } \\
\text { optical sensor) }\end{array}$ & Microwave Type \\
\hline Visual & 1 dimensional simple sensor detection 1 & 2 dimensional Visual Position Tracking \\
\hline Multiple recognition & $\begin{array}{l}\text { vehicle recognition system need to be in- } \\
\text { stalled separately. }\end{array}$ & $\begin{array}{l}\text { recognize all vehicle' ID in the Area (unlim- } \\
\text { ited no of vehicle) }\end{array}$ \\
\hline Environmental influence & $\begin{array}{l}\text { Vulnerable against port environment such as } \\
\text { snow, rain, fog etc }\end{array}$ & No Environmental influence \\
\hline Control System & Impossible & $\begin{array}{l}\text { Control of Container Control Vehicle is Pos- } \\
\text { sible }\end{array}$ \\
\hline Multiple Control & Impossible & $\begin{array}{l}\text { Recognize the number of vehicles and lane in } \\
\text { case of multiple vehicle operation. }\end{array}$ \\
\hline Loading \& unloading recognition & Impossible & Recognize loading \& unloading of container \\
\hline Moving Direction Recognition & $\begin{array}{l}\text { Additional function to recognize opposite } \\
\text { direction is needed. }\end{array}$ & $\begin{array}{l}\text { Recognize Moving Direction regardless of the } \\
\text { direction. }\end{array}$ \\
\hline Anti-vibration & $\begin{array}{l}\text { Recognition error depending on the vibration } \\
\text { of container }\end{array}$ & Safe against the vibration of container \\
\hline Unmanned Operation & Impossible & $\begin{array}{l}\text { Completely Unmanned Y/T Design is Possi- } \\
\text { ble. }\end{array}$ \\
\hline Speed Recognition & not provided & Recognize Vehicle Speed \\
\hline Maintenance Cost & High Maintenance Cost & Very little Maintenance Cost \\
\hline Position Recognition & not provided & Trance Vehicle Moving Route \\
\hline
\end{tabular}


of this technology. We think that the commercialization of this technology in the future will make great contribution to improving national and corporate competitiveness because of less financial loss due to the postponement of shipping and prompt processing of export \& import procedure by making it possible to work 24 hour a day throughout the year by unmanned cargo work regardless of external environment.

\section{References}

[1] D. H. Kim and J. Y. Song, "Ubiquitous-Based Mobile Control and Monitoring of CNC Machines for Development of u-Machine,” Journal of Mechanical Science and Technology, Vol. 20, No. 4, 2006, pp. 455-466.

[2] D. H. Kim and J. Y. Song, "Knowledge-Evolutionary
Intelligent Machine-Tool-Part 1: Design of Dialogue Agent Based on Standard Platform," Journal of Mechanical Science and Technology, Vol. 20, No. 11, 2006, pp. 1863-1872.

[3] R. Cheah, "Design and Implementation of an MMS Environment on ISODE,” Computer Communications, Vol. 20, No. 15, 1997, pp. 1354-1364.

[4] Zigbee Alliance. http://www.zigbee.org

[5] P. Bahl and V. N. Padmanabhan, "RADAR: An InBuilding RF-Based User Location and Tracking System," IEEE International Conference on Computer Communications, New Orleans, 2000, pp. 775-784.

[6] "Current Situation of Container Dock Operation," Ministry of Maritime Affair, South Korea, 2007.

[7] “Analysis Report of World's Major Terminals,” Cargo System, 2005. 